ARTIGO

\title{
LICENCIATURAS EM EDUCAÇÃO DO CAMPO NAS CIÊNCIAS DA NATUREZA: UM OLHAR PARA SUAS ESPECIFICIDADES
}

TAMINE SANTOS SÁUL'

ORCID: https://orcid.org/0000-0001-6746-9725

CRISTIANE MUENCHEN ${ }^{\mathrm{ii}}$

ORCID: https://orcid.org/0000-0003-3144-0933

\begin{abstract}
RESUMO: A presente pesquisa tem como foco um olhar sobre uma das especificidades da Educação do Campo. Assim, partindo do problema de pesquisa: "De que forma a interdisciplinaridade é apresentada nas Licenciaturas em Educação do Campo, na Área de Ciências da Natureza, no RS?”, que se insere em uma pesquisa mais ampla em nível de mestrado, buscou-se aprofundar o olhar da interdisciplinaridade nas especificidades, a partir da Análise Textual Discursiva como metodologia de análise. As análises permitiram identificar que existem especificidades para as Licenciaturas em Educação do Campo presentes nos documentos e que vem sendo seguidas pelos cursos, como a Formação por Área do Conhecimento, a Pedagogia da Alternância e, a Agroecologia, a Sustentabilidade e o Território, as quais colaboram para que a interdisciplinaridade aconteça.
\end{abstract}

Palavras-chave: Educação do Campo, Ciências da Natureza, Interdisciplinaridade, Formação por área.

\section{TEACHER'S FORMATION ON RURAL EDUCATION: A LOOK AT THE SPECIFICITIES IN THE FIELD OF}

\section{NATURAL SCIENCES}

\begin{abstract}
The present research focuses on one of the specificities of Field Education. Thus, starting from the research problem: "In what way is the interdisciplinarity presented in the Degree in Rural Education in the Area of Natural Sciences in the State of Rio Grande do Sul?", which is part of a broader research at the master's degree. It aims to deepen the interdisciplinary approach in the specificities, using the Discursive Textual Analysis as a methodology. It was possible to identify that there are specificities for the Rural Education Degrees present in the documents and that have been followed by the courses, such as the Training by Area of Knowledge, the Pedagogy of Alternation and Agroecology, Sustainability and Territory, which collaborate to happen the interdisciplinarity.
\end{abstract}

Keywords: Field Education, Sciences of Nature, Interdisciplinarity, Training by area.

\section{GRADUACIÓN EN EDUCACIÓN DEL CAMPO EN CIENCIAS DE LA NATURALEZA: UNA MIRADA A SUS ESPECIFICACIDADES}


RESÚMEN: Esta investigación se centra en una mirada a una de las especificidades de la educación del campo. Por lo tanto, a partir del problema de investigación: "¿Cómo se presenta la interdisciplinariedad en la graduación en Educación del campo, en el área de Ciencias Naturales, en RS?", desarrollada en una investigación más amplia a nivel de maestría, tiene la intención de profundizar el aspecto de la interdisciplinariedad en las especificidades, desde el análisis textual discursivo como metodología. Las análisis permitieron identificar que hay especificidades para los títulos de Licenciatura en Educación Rural presentes en los documentos y que han sido seguidos por cursos, tales como Capacitación por Área de Conocimiento, Pedagogía de Alternancia y, Agroecología, Sostenibilidad y Territorio, que colaboran para que ocurra la interdisciplinariedad.

Palabras clave: Educación del Campo, Ciéncias de la naturaliza, Interdisciplinariedad, Formación por área. 


\section{INTRODUÇÃO}

A Licenciatura em Educação do Campo desde o seu surgimento e, com todos os seus desafios, possui, de acordo com Molina (2015), cinco elementos estruturantes:

[...] promover o ingresso dos sujeitos camponeses na Educação Superior; garantir o protagonismo dos movimentos sociais do campo na sua execução; se vincular organicamente com as lutas e com as Escolas do Campo; materializar-se a partir da Alternância pedagógica; promover a formação do trabalho docente multidisciplinar, a partir das áreas de conhecimento [...] (p. 148, grifo nosso).

Nesse sentido, entende-se, a partir do último ponto, grifado na citação, que a formação desses docentes, que irão atuar nas Escolas do Campo, deva ser por área do conhecimento, favorecendo a atuação multidisciplinar. Essa proposta visa uma formação por área baseada em um projeto de transformação da escola atual, repensando dois dos seus aspectos estruturantes:

[...] a alteração da lógica de constituição do plano de estudos, visando a desfragmentação curricular pela construção de um vínculo mais orgânico entre o estudo que se faz dentro da escola e as questões da vida dos seus sujeitos concretos; e a reorganização do trabalho docente, objetivando superar a cultura do trabalho individual e isolado dos professores (CALDART, 2011, p. 97, grifos nossos).

Isso significa superar essa visão arcaica de escola, considerando a realidade dos discentes e buscando a contextualização em sala de aula, de modo que o conhecimento construído pelos sujeitos do campo seja realmente significativo e permita melhores condições de vida. Assim, é importante ressaltar que olhares e ações pelo viés interdisciplinar são um caminho que se quer para a formação inicial de educadores do campo, a qual é uma realidade ímpar no contexto da educação (CALDART, 2011).

É nesse sentido que a interdisciplinaridade deve colaborar para a formação tanto inicial de educadores do campo, quanto nos currículos das escolas básicas, afinal, ela “[...] vem com a proposta de romper com a fragmentação das disciplinas, das ciências, enfim, do conhecimento.” (THIESEN, 2008, p. $549)$.

Paiter (2017) traz inúmeros questionamentos, já na introdução de sua pesquisa, dentre eles, preocupada com a questão da interdisciplinaridade na formação por área de conhecimento/multidisciplinar, está:

Que perspectiva/compreensão de interdisciplinaridade permeia a prática educativa dos professores formadores nas Ledocs, considerando as suas trajetórias de formação inicial em cursos que tem como foco uma atuação em uma única disciplina? (PAITER, 2017, p. 17).

Nessa problematização, fica explícita a preocupação com a formação inicial dos professores formadores das Ledocs ter sido focada na atuação docente apenas para o Componente Curricular do determinado curso, o que fragmenta e corrobora com uma prática de ensino disciplinar, já que não 
tiveram formação adequada para promoverem práticas interdisciplinares e sim, por área do conhecimento.

Assim como para Britto (2011, p. 166), ficam algumas questões que nos provocam sobre tal temática:

\footnotetext{
-Como isso se aplica de forma prática na formação de professor@s?

-Em especial, na área de CN e MTM, como superar as rígidas barreiras interdisciplinares dos campos de conhecimento: Biologia, Química, Física e Matemática?

-Como a formação por área de conhecimentos pode contribuir com uma prática educativa reflexiva e inovadora perpassada por uma postura político-pedagógica e pedagógica-política?
}

Nesse sentido, justifica-se o presente trabalho, que é um recorte de uma pesquisa mais ampla, realizada na Universidade Federal de Santa Maria - UFSM, em nível de mestrado. A pesquisa buscou responder ao seguinte problema: "De que forma a interdisciplinaridade é apresentada e trabalhada nas Licenciaturas em Educação do Campo, na Área de Ciências da Natureza, no RS?”, o qual resultou em três categorias finais emergentes: 1. Especificidades das LEDOC's (Formação por área do conhecimento das LEDOC's; A Pedagogia da Alternância (PA) como articuladora da Interdisciplinaridade nas Ledoc's; Agroecologia, Sustentabilidade e Território) 2. Possibilidades de interdisciplinaridade nas Ledoc's (Eixos, temas e Complexos de estudo; Tema Gerador (TG); Disciplinas mediadoras da interdisciplinaridade nas LEDOC`s) e 3. Desafios para a prática da interdisciplinaridade nas Ledoc's. Neste trabalho, discutiremos apenas a primeira categoria: 1. Especificidades das LEDOC's e suas subcategorias, já mencionadas.

\section{A INTERDISCIPLINARIDADE E A ÁREA DO CONHECIMENTO}

O entendimento de um curso de licenciatura por área do conhecimento, multidisciplinar (e não, disciplinar), segundo a experiência da UFMG, iniciada em 2008, permite perceber a riqueza de possibilidades dessa prática para a escola e, segundo Rocha (2011), o avanço na superação do formato estruturado em torno das disciplinas é desafiador.

Outro desafio para a Educação do Campo é "A ruptura com as tradicionais visões fragmentadas do processo de produção de conhecimento, com a disciplinarização da complexa realidade sócioeconômica do meio rural na atualidade [...]" (MOLINA, 2011, p. 48), que, para Jesus (2011), pode dar-se por meio dos Círculos de cultura (CC).

De acordo com Fiori (2014, p. 15), nos CC "Encontram-se e reencontram-se todos no mesmo mundo comum e, da coincidência das intenções que o objetivam, ex-surge a comunicação, o diálogo que criticiza e promove os participantes do grupo", sendo eles, capazes de expressar juízos.

Assim, a formação por área é um modo de organização que articula componentes disciplinares, por meio de uma abordagem ampliada de conhecimentos que objetivam dialogar entre si, a partir de 
recortes da realidade, superando a fragmentação, buscando a compreensão da totalidade e da complexibilidade da realidade (MOLINA, 2011).

A organização em área do conhecimento pode ser vista de duas formas: como organização curricular ou como método de trabalho pedagógico. Dessa maneira, trata-se de uma profunda mudança na organização do trabalho docente, e, independente de estarmos tratando da Educação Básica ou Superior, tem a perspectiva de comprometer-se no processo formativo dos educadores e na gestão das instituições, a partir de mudanças (MOLINA, 2011).

Ainda sobre a organização por área, também para Caldart (2011), ela pode ser vista em dupla perspectiva. A primeira, de viabilizar a criação de mais escolas do campo (docentes multidisciplinares) e, a segunda, de oportunizar equipes docentes, por área de conhecimento, que superem a lógica da fragmentação curricular, fortalecendo um trabalho integrado.

As escolas do campo têm fechado suas portas nos últimos anos em função da pouca procura e do número insuficiente de estudantes nas turmas. Sendo assim, a partir da necessidade delas, é fundamental pensar os motivos e as estratégias para reverter esses fatos.

Segundo Molina (2015, p. 156), "Para que estas novas graduações possam cumprir os desafios para os quais foram desenhadas [...]", é imprescindível a presença dos Movimentos Sociais. Trata-se de contribuir para a formação de educadores do campo vinculados às lutas sociais e sua permanência nesses territórios.

Assim sendo, o perfil dos educadores do campo, a partir das Licenciaturas em Educação do Campo, desde sua concepção, visa um olhar pelas lutas pela terra, pela manutenção dos territórios, pela construção de novas escolas e o não fechamento das já existentes, pelo acesso à água, pelas práticas agroecológicas e pela soberania alimentar e não pelo agronegócio, enfim, por todos os desafios que dão sentido à concepção e ao perfil de educadores do campo (MOLINA, 2015).

Sobre a formação de docentes para a Educação do Campo, segundo Caldart (2011), a primeira convicção é de que o Projeto Político Pedagógico da Licenciatura em Educação do Campo, não deve estar centralizado na docência por área do conhecimento, mas sim deva ser apenas uma ferramenta para desenvolver a docência, que dê conta de refletir sobre os caminhos da transformação da escola do campo.

De tal modo, a organização curricular por área do conhecimento tem como desafio a habilitação para a docência por área e, também, a superação de um educador meramente transmissivo. Entretanto, que não descuide do conhecimento historicamente produzido pela humanidade, objetivando a transformação da realidade e, para isso, sua compreensão (CALDART, 2011). Para Freire (2015, p. 29), “Conhecer é tarefa de sujeitos, não de objetos. E é como sujeito, e somente enquanto sujeito, que o homem pode realmente conhecer". 
Dessa maneira, a formação por área não pode se restringir apenas às disciplinas, mas à apropriação de conhecimentos que já são frutos de esforços interdisciplinares (CALDART, 2011). Em se tratando da área:

A formação específica deve garantir o domínio das bases das ciências a que correspondem as disciplinas que hoje compõem sua área de habilitação, o que quer dizer trabalhar no curso os conceitos estruturadores e básicos e a epistemologia de cada disciplina (CALDART, 2011, p. 118).

Segundo Brick et al (2014), a possibilidade dos cursos de licenciatura em Educação do Campo serem disciplinares foi descartada por dois motivos. O primeiro deles, por ser inviável manter um docente por disciplina nas escolas do campo, que geralmente possuem um número muito reduzido de estudantes, principalmente nas etapas finais da educação básica, bem como pela necessidade de completar a carga horária em diversas escolas, em função da distância; o segundo, pela dificuldade de por em prática os objetivos formativos mais amplos do curso em questão.

Nesse sentido, para Rodrigues (2011, p. 126), podem ser identificados alguns limites, tais como: “[...] a dificuldade de pensar e agir como área, em contraponto a formação disciplinar dos educadores responsáveis por planejar e conduzir as práticas [...]", a escassez de tempo para planejamento, dificuldade em estabelecer diálogo com as demais áreas, entre outros.

Deste modo, ficam as seguintes questões de Rodrigues (2011, p. 126): o “[...] que seria, de fato, uma formação por áreas de conhecimento, quais os elementos que a diferenciam de uma formação específica e disciplinar e como operacionalizá-la efetivamente nas aulas?”. A partir dessas questões, o próprio autor entende que a interdisciplinaridade é a possibilidade de superação dos limites até aqui apresentados, como um fazer novo, que seja capaz de articular os saberes das diferentes disciplinas, seja através da utilização de um tema ou do trabalho integrado e coletivo, etc.

É nesse sentido que, para Rodrigues (2011, p. 141), “O currículo da escola deve ser entendido como a organização de tempos e espaços do processo educativo, visando a construção de conhecimento [...]", envolvendo a totalidade da escola. Para isso, as áreas do conhecimento devem ser compreendidas como importantes para a docência, na implementação da interdisciplinaridade para aprendizagens significativas e produção de conhecimentos científicos (RODRIGUES, 2011).

Segundo Britto (2011), foram delineadas algumas proposições para a elaboração dos planos curriculares, tais como o diálogo entre as disciplinas, a superação da visão fragmentada dos tradicionais currículos, a seleção de temas integradores, a pesquisa, a relação teoria/prática e o protagonismo estudantil.

Portanto, de acordo com o mencionado, também é necessário repensar: o que é ciência? Que, para a mesma autora: 
[...] é importante condicionar essas reflexões à clareza de uma concepção de Ciência, compreendida como uma atividade humana, ou seja, social, histórica e cultural, que não é neutra nem linear e é produzida a partir da interação entre sujeito e realidade social, contrapondo-se a visão mecanicista (BRITTO, 2011, p. 173).

Segundo Paiter (2017), é importante considerar o trabalho coletivo docente na formação por área do conhecimento, para a formação das Licenciaturas em Educação do Campo. E, também, a questão da área do conhecimento existe para suprir as demandas das escolas do campo, pois há distâncias consideráveis entre as escolas, que ocasionam o problema de deslocamento desses educadores, por não conseguirem completar sua carga horária em apenas uma escola.

Assim, a área das Ciências da Natureza, segundo Jesus (2011, p. 157), “[...] objetiva explicar os fenômenos da natureza e suas relações com o homem e com os construtos intelectuais oriundos dessa relação”. Ainda, segundo Jesus (2011), ela se caracteriza por ser uma elaboração/construção humana, portanto, interfere no construto social e cultural.

A Ciência é uma construção humana e ensinar Ciência passa por um processo de construção e reconstrução do conhecimento. É possível aprender de muitos modos, e a vivência permite uma série de experiências e concede a oportunidade de envolvimento e reflexão sobre diversas situações e assuntos (LOPES \& BIZERRIL, 2014, p. 207).

Sobre a área de conhecimento e o processo de reorganização curricular, segundo Britto (2011, p. 170), as contribuições de pesquisadores que realizam seus estudos baseados nas categorias de “[...] dialogicidade, problematização, contradição e interdisciplinaridade como orientadoras das reflexões/ações na prática educativa desenvolvidas na interface entre as teorias freireanas, currículo e Educação em CN [...]", são importantes.

Assim, os debates sobre a formação por áreas de conhecimento "[...] tiveram que contemplar algo imprescindível, a interdisciplinaridade, na medida em que, uma abordagem por área remete à diluição das rígidas fronteiras disciplinares [...]" (BRITTO, 2014, p. 68). Isso ainda implica dizer que o estudo da realidade é complexo e necessário “[...] quando é tomado como ponto estruturante para organização de um processo formativo que pretende realizar uma educação emancipatória dos sujeitos” (BRITTO, 2014, p. 68).

Tudo isso não isenta dizer que, ao construir um currículo de ciências, não haverá um recorte do conhecimento científico por parte do docente, o qual omitirá ou priorizará alguns conhecimentos, mas sim, que isso precisa ser feito com autonomia e a partir da realidade dos educandos. Uma ideia, segundo Bizerril (2014), é partir de temas que surjam de questões-problema, com o intuito de problematizar a realidade dos discentes, utilizando do conhecimento científico como apoio para a construção de uma visão crítica e, se possível, oportunizando ações concretas de transformação das situações vivenciadas. 
Dessa forma, "Ensinar Ciências requer envolvimento com questões reais e concretas, disponibilidade para o trabalho interdisciplinar e coletivo, além de estratégias para a materialidade de cada situação" (LOPES \& BIZERRIL, 2014, p. 205).

Para Paiter (2017), os componentes curriculares da área de Ciências da Natureza têm certo olhar para a realidade ou recortes da mesma, o que colabora e colaborou para a fragmentação e especialização ao longo do tempo, porém mantendo sempre certa complementariedade entre Biologia, Física e Química, que as torna uma área ampla.

Significa que a interdisciplinaridade na área do conhecimento poderá acontecer, se houver diálogo e trabalho coletivo. Defende-se que a formação multidisciplinar, ou seja, por área do conhecimento, nesse caso, sirva para que o docente desta área possa planejar com os colegas das outras áreas e possa, a partir de um tema comum à todos, decidir quais os conteúdos científicos necessários a sua compreensão interdisciplinaridade.

A questão é um ensino voltado a uma determinada realidade, valorizando-a. Nesse sentido, Brick (2017) destaca que outro projeto de sociedade seja possível, menos injusto e, também, desafiador, ao estabelecer relações entre o mais particular e universal da área. Ao tratar da área, o mesmo autor diz que, nas ciências da Natureza, o objeto de ensino deve ter como referência a realidade, ou seja, é preciso ensinarmos a partir da realidade do mundo vivido.

A educação na sua forma atual não permite que os sujeitos possam transformar a realidade. Estamos há décadas reproduzindo uma educação alienante, na qual o estudante não vê sentido algum (COSTA $e t$ al, 2017). Por isso, muitas vezes escutamos o discente clamar nas aulas: "Pra que eu vou usar isso?” e, na maioria das vezes, os docentes respondem que é para o futuro, mas esse futuro nunca chega. O estudante precisa ver sentido no agora e isso só é possível quando se trata de sua realidade, do seu pertencimento, em que seus conhecimentos sejam valorizados.

Nesse mesmo viés, Auler e Roso (2016, p. 373) destacam três dimensões necessárias: “[...] a busca de currículos temáticos, a interdisciplinaridade e a construção de uma cultura de participação em processos decisórios", entretanto para que essa última dimensão ocorra, articular as demais com a realidade é fundamental.

Outra preocupação de Auler e Roso (2016) é de que:

[...] se não tivermos uma compreensão dos limites colocados pela organização espaço-temporal da escola, podemos nos iludir reduzindo o não avanço, de práticas mais interdisciplinares, à formação deficiente dos professores, a uma suposta falta de vontade dos mesmos. Uma responsabilização, única, do sujeito professor. Essas problematizações querem sinalizar a necessidade de rupturas na organização espaço-temporal da escola, sem as quais, possivelmente, ficaremos, por um longo tempo, reféns das sempre "práticas possíveis", pontuais, não amplificadas (AULER e ROSO, 2016, p. 384). 
Essa não é uma preocupação desnecessária, pelo contrário, há a necessidade de enxergarmos os desafios, para criarmos estratégias de superá-los. No entanto, com a formação por área do conhecimento, da Educação do Campo, muitos desses empecilhos não aconteceriam, pois a dinâmica dessa modalidade de educação colaborava para a superação desses desafios.

Na próxima seção, apresentamos os encaminhamentos metodológicos da presente pesquisa.

\section{ENCAMINHAMENTOS METODOLÓGICOS}

Nesta seção, pretende-se apresentar e justificar os recursos metodológicos para o processo de busca e análise, segundo o problema e objetivos desta pesquisa, assim como caracterizar os sujeitos envolvidos.

Tendo em vista o contexto apresentado e o problema de pesquisa: "De que forma a interdisciplinaridade é apresentada nas Licenciaturas em Educação do Campo, na área de Ciências da Natureza, no RS?", observamos ser necessário mapear e analisar como os cursos de Licenciatura em Educação do Campo, com habilitação em Ciências da Natureza, do Estado do Rio Grande do Sul, vêm apresentando a interdisciplinaridade, quer na teoria (no currículo pré-escrito) por meio de seus PP's, quer na prática, a partir da análise de entrevistas com os coordenadores dos respectivos cursos.

Diante deste objetivo geral do projeto, outras questões geraram os objetivos específicos: mapear os cursos de Licenciatura em Educação do Campo, com habilitação em Ciências da Natureza, no RS, para posterior análise da forma que as especificidades da interdisciplinaridade estão presentes nos seus PP’s, bem como o entendimento de como as coordenações as compreendem.

Assim, em um primeiro momento, foram mapeados os seis locais em que ocorrem os cursos de Licenciatura em Educação do Campo, no RS e, posteriormente, analisados os seus PP's. No segundo momento, pensou-se em um roteiro para entrevista com seus coordenadores, de modo a ter mais subsídios para a análise.

A presente pesquisa é qualitativa. Apresenta-se do tipo estudo de múltiplos casos (GIL, 2006), o que garante que o problema seja analisado por meio de delineamento, sendo a unidade-caso a Licenciatura em Educação do Campo; o contexto, o Rio Grande do Sul; e os múltiplos casos, as cinco Instituições de Ensino Superior (IES), que proporcionarão evidências em diferentes contextos, em uma pesquisa com maior qualidade.

Além disso, este estudo se caracteriza como exploratório, pois está se utilizando de pesquisa bibliográfica (PP’s); descritiva, pela preocupação com a atuação prática, e, ainda, explicativa, por aprofundar o conhecimento da realidade (GIL, 2006).

A pesquisa utiliza da Análise Textual Discursiva (ATD) (MORAES E GALIAZZI, 2013) como metodologia de análise, sendo analisados os PP’s e a transcrição das entrevistas com os coordenadores, 
a partir de categorias emergentes, que foram desenvolvidas em três fases: unitarização, categorização e metatexto (MORAES \& GALIAZZI, 2013).

Em um primeiro momento, durante o final do primeiro semestre de 2017, buscaram-se nas Instituições de Ensino Superior brasileiras, quais eram os cursos de Licenciatura em Educação do Campo, com Habilitação em Ciências da Natureza, no Rio Grande do Sul, encontrando-se 6 cursos (locais) ao total, com o objetivo de constituir o corpus de análise.

A partir disso, a busca seguiu nos sites dessas Instituições Superiores de Ensino (IES), pelos PP's. Nessa pesquisa, foi possível encontrar 5 PP's, das 5 IES existentes, dos 6 locais/cursos, pois as instituições do Litoral Norte e Porto Alegre adotavam o mesmo PP.

Para a primeira etapa da ATD - a unitarização - foi utilizada a sigla PP, que significa Projeto Pedagógico, seguido por um “_” e depois um número de 1 a 5 , que corresponde aos 5 PP’s, das 5 Instituições Superiores de Ensino - objetos deste estudo, como demonstrado no quadro abaixo:

Quadro 1: Siglas e locais das IES.

\begin{tabular}{|c|c|}
\hline SIGLA: & LOCAL: \\
\hline PP_1 & UNIPAMPA - Dom Pedrito \\
\hline PP_2 & UFFS - Erechim \\
\hline PP_3 & $\begin{array}{c}\text { UFRGS - Porto Alegre e Litoral } \\
\text { Norte }\end{array}$ \\
\hline PP_4 & FURG - São Lourenço do Sul \\
\hline PP_5 & IFFAR - Jaguari \\
\hline
\end{tabular}

Fonte: autora 1.

Ainda, após o número cardinal, para cada unidade da mesma IES, foi utilizada uma letra maiúscula, seguindo a sequência do alfabeto. As unidades foram selecionadas sempre buscando olhar para o problema de pesquisa.

Para cada unidade selecionada, criou-se um resumo, frase que sintetizasse os pontos mais relevantes da unidade, para facilitar a segunda etapa da ATD - a categorização. Assim, o quadro das unidades ficou da seguinte forma:

Quadro 2: Modelo de quadro das unidades.

\begin{tabular}{|c|c|c|}
\hline SIGLA: & UNIDADE: & RESUMO: \\
\hline PP_1A & & \\
\hline
\end{tabular}

Fonte: autora 1.

Como exemplificado, a sigla PP, nesse caso, refere-se ao Projeto Pedagógico de Dom Pedrito, por isso 1 . Sendo a $1^{\text {a }}$ unidade, por isso a letra $A$. 
Após a análise dos PP's, entendeu-se como necessário realizar entrevistas com os coordenadores dos cursos em questão, com vistas a ampliar a análise dos textos dos PP’s e responder o problema de pesquisa, estendendo o metatexto, já inicialmente escrito.

Durante o primeiro semestre de 2018, entrou-se em contato com os coordenadores dos cursos já mencionados, para agendar as entrevistas. Os critérios de seleção dos coordenadores para a realização da entrevista foram: os últimos coordenadores, com no mínimo um a dois anos de gestão, enquanto coordenador. As entrevistas foram realizadas já no início do segundo semestre do ano que decorre, via Skyppe, com exceção de uma entrevista que foi por telefone, em função do campus de que se trata não possibilitar uma boa conexão de internet. Assim, as entrevistas foram gravadas e, posteriormente, transcritas, sendo que de 6 coordenadores, conseguiu-se entrevistar 5 , pois não tivemos retorno do sexto.

As entrevistas foram realizadas a partir de um questionário semiestruturado: 1. Para você, existem elementos estruturantes necessários à formação dos licenciandos em Educação do Campo? Se sim, qual ou quais seriam? 2. O curso tem trabalhado na perspectiva da interdisciplinaridade? Se sim, de que forma? 3. Quais os desafios desse tipo de trabalho? Como eles vêm sendo enfrentados no curso? 4. Você já ouviu falar sobre Temas geradores? Se sim, responda as próximas perguntas: Seriam dessa forma, os Temas Geradores, viáveis nas Licenciaturas em Educação do Campo? Eles indicam uma nova forma de organização das disciplinas, o que aproximaria o currículo de algo integrado, rumo à interdisciplinaridade, sendo favorecido nesse contexto pelo TA e TC, de acordo com a PA?

Após realizar as entrevistas e transcrevê-las, foram selecionadas as unidades de significado, as quais integraram as categorias intermediárias. Assim, o quadro dessas unidades ficou da seguinte forma:

Quadro 3: Modelo de quadro das unidades.

\begin{tabular}{|c|c|c|}
\hline SIGLA: & UNIDADE: & RESUMO: \\
\hline E_1 $^{\text {a }}$ & & \\
\hline
\end{tabular}

Fonte: autora 1

A sigla $\mathrm{E}$, nesse caso, refere-se à entrevista, 1 porque foi a primeira entrevista. Sendo a $1^{\mathrm{a}}$ unidade, por isso a letra A.

Houve um trabalho de organização e reorganização das unidades de significado, o qual permitiu a construção e reconstrução das categorias em iniciais, intermediárias, até chegar às finais. A partir dessas, pode-se reestruturar o metatexto, o qual traz elementos para pensarmos sobre como a interdisciplinaridade é apresentada nas Licenciaturas em Educação do Campo.

Este artigo discute a categoria: Especificidades das LEDOC's (Formação por área do conhecimento das LEDOC's, A Pedagogia da Alternância (PA) como articuladora da Interdisciplinaridade nas Ledoc's, Agroecologia, Sustentabilidade e Território). 


\section{RESULTADOS E DISCUSSÃO}

\section{Formação por área do conhecimento das LEDOC's}

A formação por área do conhecimento é algo que já vem sendo discutido pela área, como por exemplo, a partir do problema de pesquisa do trabalho de Britto e Silva (2015, p. 764), no qual questionase sobre:

[...] como os aspectos de construção curricular coletiva, ação interdisciplinar e aproximação com a realidade investigada nos tempos de alternância vêm sendo encaminhados na busca por uma coerência teórico/metodológica para formação por área?

É possível perceber que este problema está em consonância com os aspectos analisados nesta pesquisa, assim como no problema são ressaltados aspectos fundamentais já mencionados nas referências e agora reforçados, tais como: currículo, interdisciplinaridade e realidade - uma tríade.

Para Lopes e Bizerril (2014), a formação de docentes preparados para um ensino contextualizado e interdisciplinar é preocupante, pois é necessário que os estudantes envolvam-se por interesse e curiosidade, que sejam instigados ao descobrir sua realidade em conexão com o mundo. Assim, essas preocupações com essas especificidades envolvem dizer que:

A formação de educadores que integrem diversos conhecimentos visando à superação da condição de pensamento disciplinar e fragmentado é necessária para que os educadores do campo consigam atuar de forma eficiente nas escolas em que irão desenvolver seu trabalho futuramente (LOPES \& BIZERRIL, 2014, p. 205 e 206).

Para Ferreira e Molina (2014), essa perspectiva interdisciplinar necessita de uma articulação entre a realidade: o trabalho e a vida dos sujeitos em formação com a produção do conhecimento, a partir da práxis.

Nas entrevistas, embora com menor ênfase para essa subcategoria, os docentes coordenadores ao longo de suas falas mencionam a ideia das áreas do conhecimento (E_4O), dizem considerar as diferentes áreas $($ E_1H) e, ainda, que elas "[...] precisam se relacionar para que a interdisciplinaridade aconteça [...]" (E_4P).

Assim, a intencionalidade deste curso é formar:

[...] um educador que prime pelo trabalho docente, articulando os saberes sistematizados aos saberes que se enlaçam às práticas dos sujeitos que vivem no campo. Para tanto, indica como princípios metodológicos: o diálogo, a problematização, a contextualização, a interdisciplinaridade, a relação teoria-prática, a humanização, a ética e o compromisso com a transformação. De acordo com as diretrizes curriculares, devem constituir preocupações num curso de formação de professores a democratização dos espaços escolares; a autonomia da escola e dos docentes; a emancipação do sujeito como forma de exercer plenamente a sua cidadania; a pertinência e relevância social do conhecimento; a ética como base das relações humanas e sociais e a sensibilidade afetiva e estética em relação a si, ao outro e ao meio (PP_2C, p. 30). 
Porém, um dos desafios diz respeito à prática interdisciplinar, pois “[...] apesar de enredado nas fronteiras das disciplinas que dão sustentação teórica metodológica, as áreas representadas no curso [...]” (PP_2C, p. 30) devem criar espaços para propostas metodológicas interdisciplinares para se concretizarem na prática das escolas.

Uma possibilidade exemplificada por um dos coordenadores para superar esses desafios foi a seguinte: “[...] então nós temos um critério que é um docente das áreas das humanas e um docente das Ciências da Natureza, entrando junto em sala de aula para trabalhar o componente: prática pedagógica.” (E_3U) - o que se torna um caminho possível e necessário.

Para que todas as especificidades saiam da teoria e atinjam o campo da prática, é necessário um currículo bem fundamentado, ou seja, segundo Ferreira e Molina (2014, p. 131) é necessário:

[...] um projeto de escola que se articula com os projetos sociais e econômicos do campo, a partir da perspectiva de um projeto popular de desenvolvimento, e que cria e estabelece uma conexão direta entre formação e produção, entre educação e compromisso político. Uma escola que, em seus processos de ensino e de aprendizagem, considera o universo cultural e as formas próprias de aprendizagem dos povos do campo, que reconhece e legitima esses saberes construídos a partir de suas experiências de vida; uma escola que se transforma em ferramenta de luta para a conquista de seus direitos como cidadãos e que forma os próprios camponeses como os protagonistas dessas lutas e intelectuais orgânicos da classe trabalhadora (FERREIRA \& MOLINA, 2014, p. 131).

Uma das premissas para a Educação do Campo é a formação por área do conhecimento, para atender as suas necessidades, já justificadas na revisão teórica deste trabalho. Para tanto, a área em questão, das Ciências da Natureza, analisada nos PP's do RS, mencionam esses aspectos já tratados, como por exemplo, a carência de educadores nas escolas do campo, que é grande, tendo inclusive, docentes atuando e não habilitados (PP_2A, p. 23 e 24). Assim, em outro PP, a grande questão da formação de educadores para o campo é: "Como não reproduzir a mesma formação de licenciandos que vêm “desescolarizando” o campo?” (PP_1C, p. 36). Nesse sentido, é necessário considerar que:

[...] as longas distâncias e a baixa densidade demográfica exigem a formação de professores (as) por área de conhecimento e que estejam atentos às práticas pedagógicas que considerem os diversos ciclos da vida e seus processos de aprendizagem, que se vincule ao trabalho como princípio educativo e que sejam capazes de problematizar, a partir do contexto em que a escola está inserida sem se restringir a ele (PP_1C, p. 36).

Segundo Ghedini et al (2014, p. 86), a Educação Popular, concebida por Freire na obra Pedagogia do Oprimido (2014), vem a ser a alavanca para possibilidades na vida dessas comunidades do campo, a partir do conhecimento, no âmbito dos Movimentos Sociais, com o horizonte em um projeto histórico de luta de classes.

Em alguns dos PP’s, são necessárias novas posturas teórico-metodológicas para que seja possível a construção de conhecimento, o que envolve a interdisciplinaridade e, para isso, o "[...] desenvolvimento 
de ações coletivas, em cooperação, num trabalho articulado entre as diferentes áreas que constituem a matriz curricular do curso" (PP_2E, p. 46).

Assim, demonstrou-se nos PP’s e, também, nas entrevistas, que são incompatíveis toda e quaisquer posturas individuais, pois a interdisciplinaridade requer troca, cooperação, articulação de saberes, trabalho integrado, diálogo, trabalho em equipe, participação, conhecimento da realidade, pesquisa, problematização (PP_2E, p. 46).

Além disso, a interdisciplinaridade pode ser vista:

[...] como uma estratégia de integração metodológica, seja para fins tecnológicos, epistemológicos, ou pedagógicos, podendo gerar novos campos de conhecimento, ou procedimentos inovadores para responder a novas necessidades sociais (PP_3C, p. 8 e 9).

E, ainda, uma forma de:

Organizar os componentes curriculares em áreas do conhecimento de forma interdisciplinar com ênfase nas Ciências da Natureza, de modo que os estudantes possam vivenciar na prática de sua formação a lógica do trabalho pedagógico para o qual estão sendo preparados (PP_3C, p. 8 e 9).

Para tanto, os objetivos dos cursos são: "Formar professores para o exercício da docência multidisciplinar em Escolas do Campo nas áreas de Ciências da Natureza [...]” (PP_5A, p. 18), assim como "Desenvolver estratégias de formação para a docência interdisciplinar em uma organização curricular por áreas do conhecimento nas escolas do campo e outros espaços educativos” (PP_3E, p. 10).

Dessa forma, para tentar dar conta da complexidade da interdisciplinaridade, os cursos elaboraram um eixo temático por semestre, composto pelos componentes curriculares com temáticas comuns à área, ou seja, a organização curricular é uma estratégia que busca possibilitar "[...] práticas interdisciplinares investigativas associadas ao tripé ensino-pesquisa-extensão.” (PP_1H, p. 51).

A formação por área, então, torna o docente:

[...] apto para atuar nos componentes de Ciências nos anos finais do Ensino Fundamental e nos componentes de Química, Física e Biologia ou na respectiva área de conhecimento do Ensino Médio, na Modalidade Educação de Jovens e Adultos e na combinação com a Educação Profissional. Também poderá participar na elaboração e execução de projetos educativos, bem como em instituições de Assistência Técnica e Extensão Rural. Desenvolver projetos pedagógicos interdisciplinares na área de Ciências da Natureza em espaços educativos escolares e comunitários, organizações não governamentais, órgãos públicos ou privados e movimentos sociais (PP_1E, p. 37).

Nesse sentido, essa formação por área objetiva que haja contribuição por parte dos egressos “[...] na superação da disciplinarização dos saberes, ainda hegemônica nos currículos escolares em geral" (PP_3B, p. 4 e 5). Para isso, é necessário que no seu cotidiano, o licenciando vivencie a valorização e a construção de conhecimentos, a contextualização a partir da articulação das disciplinas do curso. Assim, os "[...] conhecimentos serão abordados a partir de situações-problema reais, organizadas semestralmente 
dentro de temas geradores e transversalizadas por temáticas interdisciplinares contemporâneas, [...]" (PP_3B, p. 4 e 5), desde que os conteúdos sejam contemplados (PP_3B, p. 4 e 5).

Segundo Ferreira \& Molina (2014, p. 135):

[...] o conhecimento não corresponde imediatamente à reprodução da realidade, mas, de modo elementar, corresponde ao produto de elaboração do material que, no processo de conhecimento, o sujeito se defronta. Trata-se, então, de um ato de transgressão sobre aquilo que está à vista, o óbvio, na medida em que o sujeito enfrenta o conteúdo e a forma que o objeto aparentemente se apresenta ao sujeito, buscando sua história, espaços e tempos que constituíram sua essência - sujeito e objeto se relacionam dinamicamente no processo de criação que encerra a essência do objeto a ser conhecido.

São necessários, no caso do curso que habilita para Ciências da Natureza - nosso foco de análise -, “[...] conhecimentos de diversos campos do saber, como: a Matemática, a Biologia, a Física, a Química, a Educação, a Informática, a Agroecologia, dentre outros [...]” (PP_2D, p. 45). Com isso, o processo de organização, desenvolvimento e construção de conhecimentos é ressignificado e, nesse caminho:

[...] a interdisciplinaridade se apresenta como uma maneira precípua para promover uma formação integrada e articulada com a realidade social, política, econômica e cultural, que exige sempre mais uma formação cidadã, consciente, crítica, reflexiva, emancipatória (PP_2D, p. 45).

Assim, quatro dos cinco PP's e quatro dos cinco entrevistados fomentam que o trabalho por área do conhecimento é auxiliado pela interdisciplinaridade, tanto na área quanto entre as áreas do conhecimento.

\section{A Pedagogia da Alternância (PA) como articuladora da Interdisciplinaridade nas Ledoc's}

Segundo Ferreira e Molina (2014), apresentam-se dois grandes desafios no âmbito das Licenciaturas. O primeiro deles, que os docentes estejam conscientes sobre a importância da interação, da articulação entre as áreas do conhecimento e, ainda, que seja proposta uma nova programação curricular interdisciplinar, que considere a realidade vivenciada, em especial, os fatores socioeconômicos. O segundo, que o TC seja usado como ferramenta de apoio para a investigação, a práxis, no contexto da comunidade.

Esse currículo estará organizado metodologicamente pela PA, entre TE e TC do Campo:

[...] a proposta curricular do curso integra e interdisciplinariza a atuação dos sujeitos educandos na construção do conhecimento necessário à sua formação enquanto educadores, não apenas nos espaços formativos escolares, mas também nos diversos espaços das comunidades onde estão localizadas as escolas de ensino fundamental do campo (PP_3D, p. 9 e 10).

Segundo Ghedini et al (2014), é em Freire que questões emergentes são analisadas baseadas nesse referencial teórico metodológico, auxiliado pela PA e, assim, esses espaçostempos são ressignificados nos 
Movimentos Sociais Populares do Campo (MSPdoC), a partir de "[...] uma ponte com a dimensão da investigação do referencial freireano" (GHEDINI et al, 2014, p. 84).

Com isso, dois dos projetos que destacam o TC enfatizam que "[...] contemplarão estudos e práticas orientadas interdisciplinares, organizados a partir de um eixo temático do semestre letivo" (PP_1I, p. 75 e 76). No mesmo PP, essas práticas interdisciplinares são entendidas como:

[...] enfrentamento coletivo de problemas provindos da realidade local, aos quais apenas uma área de conhecimento não dá conta de sua totalidade. Frente a isso, as ações interdisciplinares previstas no curso compreendem este conceito para além da integração ou superposição de componentes curriculares, mas em um processo essencialmente coletivo frente à complexidade do objeto de conhecimento (PP_1I, p. 76 - rodapé).

Ao realizar as entrevistas, três dos cinco coordenadores entrevistados percebem a relação da interdisciplinaridade com o TC, mais especificamente com a realidade, como demonstra a citação abaixo em que o docente realizou a analogia com a disciplina de Microbiologia.

C: Então assim, tem várias formas de tu dar microbiologia olhando pra esse sujeito lá. Ah o que que ele...

M: Seria de acordo com a realidade?

C: De acordo com a realidade. E esse, esse é, pelo menos assim que eu enxergo, pelo menos os professores da área, é assim que eles deveriam, eles tem que dar o básico, que é o que, todo estudante tem que pelo menos entender aquilo ali pra sair daqui, sobre aquela disciplina, mas aqui a gente tem que fazer essas ligações. Então, principalmente, com o tempo comunidade (E_2D).

Ou seja, o coordenador menciona que existem os conceitos básicos necessários para a compreensão, mas que são necessárias as ligações e, ainda, trata de enxergar o tema na comunidade, de forma contextualizada, percebendo isso como um desafio.

Então assim, se eu dou aquele tema aqui no tempo escola, como é que ele vai trabalhar lá, como é que eu vou auxiliar ele a enxergar a microbiologia lá dentro da comunidade dele, entende? Então, essas obrigações é que são extremamente difíceis (E_2E).

Já para outro coordenador, ele explica como ocorre o Regime de Alternância:

[...] ele funciona em regime de alternância, com o tempo universidade, que seria o tempo aula na universidade é janeiro, fevereiro e a primeira semana de março e depois o mês de julho e a primeira semana de agosto, isso equivale a $75 \%$ da carga horária do curso, os outros $25 \%$ é tempo comunidade, que é o desenvolvimento de projetos interdisciplinares em cada semestre, no caso o estudante de cada semestre desenvolve um projeto interdisciplinar em grupo sobre o tema gerador ou o tema do complexo daquele semestre, no caso Identidade e processo identitário. Então $25 \%$ da carga horária é reservada para o tempo comunidade nesses períodos que, no intervalo do tempo universidade, pretende desenvolver então, essas temáticas, o que possibilita então no curso ter de 65 a 70\% de estudantes do Campo (E_3S).

Para Campos et al (2015, p. 7), um modelo de licenciatura aos moldes da PA necessita de "[...] uma articulação entre as disciplinas para que o discente possa desenvolver competências capazes de habituá-lo a uma complexidade que gerencia todas as vertentes da interrelação entre disciplinas [...]”. 
Nesse sentido, tal regime é intercalado por projetos interdisciplinares sobre o tema do semestre. Também, outro coordenador diz que:

[...] o DNA da Educação do campo, que é a pedagogia da alternância, sem a pedagogia da alternância, acho que não teria a identidade, os cursos não teriam a identidade de Educação do Campo então um elemento estruturante é a pedagogia da alternância, não só a sua funcionalidade, a prática dela, mas em si toda a concepção teórica, os pilares conceituais também da pedagogia da alternância que é na relação da teoria com a prática [...] (E_4A).

[...] em algumas vezes universidades, cada componente propõe um trabalho interdisciplinar no tempo comunidade e nós discutimos que não, que não seria viável cada componente ter um trabalho interdisciplinar e depois apresentar no seminário integrador, que aí nós não teríamos essa relação de tempo comunidade com tempo universidade, com a teoria, com a provocação de olhar a unidade, de olhar a totalidade (E_4I).

As citações acima mencionadas nos permitem analisar que a PA em seus diferentes vieses - que não é o objetivo de discussão deste trabalho - colabora com a prática da interdisciplinaridade, considerando as diversas realidades e, que cada curso, organiza-se de acordo com suas possibilidades. Como exemplo, o trabalho de Campos et al (2015, p. 1), cita em um de seus objetivos: “[...] identificar qual interdisciplinaridade no PPC permite estabelecer a relação entre a Pedagogia da Alternância e o Ensino de Ciências e Matemática", pois a mesma, após análises, constata-se como um elemento estruturante articulador da interdisciplinaridade.

Assim, a Educação do Campo precisa ser emancipatória, transformadora, crítica, precisa romper paradigmas sobre produção de conhecimento, no currículo, “[...] uma vez que o Projeto Político Pedagógico traz o princípio da interdisciplinaridade na base da matriz curricular. Tal projeto também é marcado pela indissociabilidade entre teoria e prática e pela modalidade de alternância [...]" (MANICO e MARTINS, 2017, p. 125).

Nesse sentido, o que se quer é que todos esses aspectos sejam levados em consideração, de modo a contribuir na construção do conhecimento realmente significativo para os estudantes, que considere sua realidade e que não dissocie teoria e prática.

\section{Agroecologia, Sustentabilidade e Território.}

Essa subcategoria obteve menos unidades de significado, ou seja, não foi tão recorrente nas análises, porém relevante. A Agroecologia aparece em todas as entrevistas, sendo que, em um PP:

[...] sua principal meta é a formação de educadores para atuar em escolas do campo, favorecendo a reflexão e a formação adequada à permanência e produção de vida no meio rural pelo viés da agroecologia (PP_2B, p. 25, grifo meu).

Dessa forma, várias experiências que incluem a Agroecologia já existem em todos os cursos aqui referidos, tais como: 
[...] a gente tem aqui componentes curriculares na área de educação popular, de educação do campo, já no $1^{\circ}$ semestre. Tem uma ênfase em agroecologia, ah e em direitos humanos, isso voltado principalmente para os povos do campo, talvez esses sejam os elementos que eu vejo que têm mais peso, que se identificam mais com a proposta da educação do campo (E_1A, grifo meu).

E tem um elemento importante nessa discussão, é, que a gente tem bebido um pouco da fonte da agroecologia pra discutir isso também, que é a desnaturalização das pessoas e, principalmente das crianças quando se trata de educação, nos espaços de formação, enfim, nas escolas, ocorre a partir dos últimos 20, 30 anos, com pressão, resultado da pressão, do desenvolvimento modernizante da agricultura, década de 60 e 70, ocorre o processo de desnaturalização [...] (E_3A, grifo meu).

[...] é os conhecimentos de Agroecologia, nosso curso por ser Ciências da Natureza tem a Agroecologia como base e a partir dela a gente vai dialogando com o território dialogando a noção de desenvolvimento regional enfim, e estudando os conceitos da própria educação em Ciências da Natureza mesmo (E_5F, grifos meus).

A Agroecologia é uma ciência (GUBUR \& TONÁ, 2012) e traz um viés importante de ser questionado, problematizado, refletido e trabalhado sobre a Soberania Alimentar e as formas de produção.

A respeito da Sustentabilidade, no PP_1, já na justificativa social para a criação do curso, aparece a preocupação com ela, ao pensar em docentes para atuar nas escolas do campo em um contexto de sustentabilidade socioambiental, quanto com o objetivo geral “[...] de investigar questões inerentes à sua realidade e à sustentabilidade da vida no campo [...]” (PP_1O) e, ainda, nos objetivos específicos do PP_2.

Sobre a Educação Ambiental, ela é tema obrigatório e precisa permear o currículo escolar, "Formar professores, para trabalhar nessa modalidade de ensino, implica fazer abordagem interdisciplinar da temática em questão" (PP_5E, p. 29). E, ainda, no PP_3 o enfoque na sustentabilidade aparece na justificativa relacionada ao viés agroecológico, bem como nas ementas dos 5PP's.

Já se tratando de Território, ele apareceu em quatro dos cinco PP's. Surgiu como Eixos (Território e Territorialidade e Territorialidades e sustentabilidade) em dois deles (PP_1 e PP_3), mostrou-se muito nas ementas de três PP's e, ainda, muito, na fala de 2 dos coordenadores.

Território se caracteriza como:

Este caráter complexo do desafio da formação humana em Educação do Campo fundamentase, por sua vez, na concepção de que o campo é território de produção de vida, de produção de novas relações sociais, de novas relações entre os homens e a natureza, de novas relações entre o rural e o urbano (PP_1P).

O campo é território de produção de vida; de produção de novas relações sociais; de novas relações entre os homens e a natureza; de novas relações entre o rural e o urbano. Assim, esperase a partir destes componentes curriculares produzir um novo olhar para o campo, o que necessita ocorrer em sintonia com toda uma nova dinâmica social de valorização deste território e de busca de alternativas para melhorar a situação de quem vive e trabalha nele (PP_2G).

[...] a noção do território, como esse território é compreendido e estudado, as suas diferentes, a diferente composição do território, as instituições que existem nesse território, os espaços educativos do território, como eles se conversam entre si, isso é fundamental [...] (E_5C). 
[...] para que o aluno consiga elaborar bem esse processo de idas e vindas do tempo comunidade do tempo universidade e que para mim tem o território, e, eu acho que alternância também, seria um elemento central no próprio, na compreensão da Educação do Campo, seja qual for o modelo de alternância, mas ter essa possibilidade de você fazer um estudo, que seja, na qual o diálogo constante com a comunidade através do tempo comunidade seja parte efetiva do processo, que o aluno não vai ser um aluno como em uma outra licenciatura que vai só a partir do final do curso nos estágios tomar conhecimento do que que seria a realidade de uma escola, ele vai estar desde o primeiro semestre através da alternância conseguindo se inserir nos espaços educativos do campo (E_5D).

Assim como outros elementos estruturantes estão sendo proporcionados pela PA, o território é um articulador da interdisciplinaridade, pois é um eixo/tema da realidade camponesa, que precisa ser discutido e fomentado e, para que esse diálogo ocorra, são necessários conhecimentos de diversos campos do saber.

\section{CONSIDERAÇÕES FINAIS}

É possível perceber que a interdisciplinaridade é uma questão apresentada em todos os PP's e entrevistas e, por isso, fundamental para as Licenciaturas em Educação do Campo, colaborando com uma série de outras especificidades, tais como a formação por área do conhecimento, a PA, a Agroecologia, a Sustentabilidade e o Território.

Nesse sentido, as especificidades dos cursos de Licenciatura em Educação do Campo aparecem em todos os PP's e, nas falas dos coordenadores, de maneira a nortear essa modalidade de Educação com base nas Políticas Públicas e lutas sociais desde seus primórdios.

Sobre a formação por área do conhecimento, defende-se que a criação e implantação dos cursos por área do conhecimento alcança um avanço no ensino de ciências, com essa nova organização curricular, bem como a interdisciplinaridade, como articuladora de conhecimentos e disciplinas, fomenta a importância de conservarmos algo que foi conquistado.

A partir desse olhar para as especificidades, considera-se que a interdisciplinaridade é elemento estruturante sim, dos cursos em questão. Ela está presente nos referenciais e nos documentos que regem esses cursos, bem como na fala de seus coordenadores. Além disso, ela requer caminhos (outras especificidades) pelos quais seja possível sua implementação, seja por meio da formação multidisciplinar (área do conhecimento), pela PA ou, ainda, por Temas (Agroecologia, Sustentabilidade e Território) capazes de unir todas essas especificidades, já mencionadas.

Essas subcategorias permitiram analisar que existem especificidades para as Licenciaturas em Educação do Campo presentes nos documentos e que vêm sendo seguidas pelos cursos, as quais colaboram para que a interdisciplinaridade aconteça.

Nesse sentido, as subcategorias que emergiram dessa pesquisa demonstram especificidades, que, assim como os avanços, precisam ser conservados, afinal, políticas públicas foram fomentadas para que os cursos de Licenciatura em Educação do Campo tivessem condições de serem criados e 
implementados. A formação por área de conhecimento é um exemplo de especificidade que precisa ser conservado, pois a mesma considera a realidade da Educação do Campo e vem com uma proposta ímpar para atender essa realidade, valorizando seu contexto e suas peculiaridades. Já a PA auxilia estabelecendo essa não dicotomia entre teoria e prática e favorecendo a valorização da comunidade em que o estudante está inserido, de modo a fomentar projetos e estágios que a considerem. A Agroecologia, o Território e a Sustentabilidade também são temas provenientes do Campo e que problematizam o contexto político, histórico e social do Campo.

A interdisciplinaridade aqui defendida é muito mais do que uma metodologia, ela é uma nova maneira de entender a estrutura do currículo e de organizar os conhecimentos construídos historicamente, os quais sejam realmente necessários para a relação do homem com o mundo. Ela também estrutura a resolução de problemas complexos e reais, sendo que esses condicionam os conhecimentos necessários para a compreensão do tema e transformação da realidade do campo.

\section{REFERÊNCIAS}

AULER, D.; ROSO, C. C. A participação na construção do currículo: práticas educativas vinculadas ao movimento CTS. Ciência Educação, v. 22. N. 2., 2016. p. 371-389

BIZERRIL, M. X. A. Oportunidades e desafios para a Educação do Campo a partir do -Seminário de formação para o trabalho interdisciplinar na área de Ciências da Natureza e Matemática nas escolas do campoll. In: MOLINA, M. C. (Org.). Licenciaturas em Educação do Campo e o Ensino de Ciências Naturais: desafios à promoção do Trabalho Docente interdisciplinar. Brasilia: MDA, 2014. p. 11-125.

BRICK, E. M. Realidade e Ensino de Ciências. Tese de doutorado. Florianópolis, SC: UFSC, 2017.

BRICK, E. M.; PERNAMBUCO, M. M. C. A.; SILVA, A. F. G.; DELIZOICOV, D. Paulo Freire: interfaces entre Ensino de Ciências Naturais e Educação do Campo. In: MOLINA, M. C. (Org.). Licenciaturas em Educação do Campo e o Ensino de Ciências Naturais: desafios à promoção do Trabalho Docente interdisciplinar. Brasília: MDA, 2014. p. 23-59.

BRITTO, N. S. Formação de professores e professoras em Educação do Campo por área do conhecimento - Ciências da Natureza e Matemática. In: MOLINA, M. C.; SÁ, L. M. (Orgs.). Licenciaturas em Educação do Campo, Belo Horizonte: Autêntica Editora, 2011, p. 83-91.

, N. S. Uma trama de muitos fios - experiências, área de Ciências da Natureza e Matemática, currículo, diálogos freireanos - tecem a formação docente em Educação do Campo na UFSC. In: MOLINA, M. C. (Org.). Licenciaturas em Educação do Campo e o Ensino de Ciências Naturais: desafios à promoção do Trabalho Docente interdisciplinar. Brasília: MDA, 2014. p. 61-80.

, N. S.; SILVA, T. G. R. Educação do Campo: formação em ciências da natureza e o estudo da realidade. Educação e realidade, v. 40, n. 3, p. 763-784, jul./set. 2015.

CALDART, R. S. Licenciatura em Educação do Campo e projeto formativo: qual o lugar da docência por área? In: MOLINA, M. C.; SÁ, L. M. (Orgs.). Licenciaturas em Educação do Campo, Belo Horizonte: 
Autêntica Editora, 2011. p. 95-121.

CAMPOS, R. I.; SILVA, V. de A.; FREITAS, E. C. de.; MONTEIRO, H. S. R. Uma perspectiva interdisciplinar para o curso de Educação do Campo na Regional Goiás - UFG. X ENCONTRO NACIONAL DE PESQUISA EM EDUCAÇÃO EM CIÊNCIAS (ENPEC), Águas de Lindóia, SP - p. 1-8, 2015. Dísponível em: <http://www.abrapecnet.org.br/enpec/xenpec/anais2015/resumos/R1153-1.PDF>. Acesso em: 08. Ago. 2020.

COSTA, F. A.; COSTA, F. A.; MORENO, G. de. S. Prática do trabalho interdisciplinar em Ciências da Natureza e Matemática na Escola Municipal Nova Canaã, Jacundá/PA. In: MOLINA, M. C. (Org.). Licenciaturas em Educação do Campo e o ensino de Ciências Naturais: desafios à promoção do trabalho docente interdisciplinar Volume II. Editora Universidade de Brasília, 2017. p. 189-210.

FERREIRA, M. J. L.; MOLINA, M. C. Desafios à formação de Educadores do Campo: tecendo algumas relações entre os pensamentos de Pistrak e Paulo Freire. In: MOLINA, M. C. (Org.). Licenciaturas em Educação do Campo e o Ensino de Ciências Naturais: desafios à promoção do Trabalho Docente interdisciplinar. Brasília: MDA, 2014. p. 127-153.

FIORI, E. M. Aprender a dizer a sua palavra. In: FREIRE, P. Pedagogia do Oprimido. 57. ed. Rio de Janeiro: Paz e Terra, 2014.

, P. Pedagogia do Oprimido. 57. ed. Rio de Janeiro: Paz e Terra, 2014.

2015.

, P. Ação Cultural para a Liberdade e outros escritos. Rio de Janeiro, São Paulo: Paz e Terra,

GHEDINI, C. M.; ONÇAY, S. T. V.; DEBORTOLI, S. F. B. Educação do Campo e prática pedagógica desde um viés freireano: possibilidade de construção da consciência e da realidade. In: MOLINA, M. C. (Org.). Licenciaturas em Educação do Campo e o Ensino de Ciências Naturais: desafios à promoção do Trabalho Docente interdisciplinar. Brasília: MDA, 2014. p. 83-109.

GIL, A. C. Como elaborar projetos de pesquisa. 4ª ed. São Paulo: Atlas, 2006.

GUBUR, D. M. P.; TONÁ, N. Agroecologia. In: CALDART, R. C. (Org.) Dicionário da Educação do Campo. Rio de Janeiro, São Paulo: scola Politécnica de Saúde Joaquim Venâncio, Expressão Popular, 2012. p. 57-65.

JESUS, C. A. de. Currículo por área de conhecimento na formação de professores para escolas do campo da UFS. In: MOLINA, M. C.; SÁ, L. M. (Orgs.). Licenciaturas em Educação do Campo, Belo Horizonte: Autêntica Editora, 2011. p. 149-164.

LOPES, E. A. de. M.; BIZERRIL, M. X. A. Vídeo e Educação do Campo: novas tecnologias favorecendo o Ensino de Ciências interdisciplinar. In: MOLINA, M. C. (Org.). Licenciaturas em Educação do Campo e o Ensino de Ciências Naturais: desafios à promoção do Trabalho Docente interdisciplinar. Brasília: MDA, 2014. p. 201-229.

MANICO, H. C.; MARTINS, N. de. P. O movimento da práxis: contribuições de Paulo Freire para a promoção da Educação do Campo no município de São Domingos/GO. In: MOLINA, M. C. (Org.). Licenciaturas em Educação do Campo e o ensino de Ciências Naturais: desafios à promoção do trabalho docente interdisciplinar Volume II. Brasília: Editora Universidade de Brasília, 2017. p. 121-140.

MOLINA, M. C. SÁ, L. M. A Licenciatura em Educação do Campo da Universidade de Brasília: 
Estratégias Político-Pedagógicas na Formação de Educadores do Campo. In: MOLINA, M. C.; SÁ, L. M. (Orgs.). Licenciaturas em Educação do Campo, Belo Horizonte: Autêntica Editora, 2011. p. 35-61.

M. C. Expansão das licenciaturas em Educação do Campo: desafios e potencialidades.

Educar em Revista, Curitiba, Brasil, n. 55. Editora UFPR. jan./mar. 2015., p. 145-166.

MORAES, R. GALIAZZI, M. C. Análise textual discursiva. Ijuí: Editora Unijuí, 2013.

PAITER, L. L. Reflexões sobre a Formação Docente na Área de Conhecimento Ciências da Natureza: a Licenciatura em Educação do Campo - UFSC. Dissertação de Mestrado. Florianópolis, SC: UFSC, 2017.

ROCHA, M. I. A. DINIZ, L. de S. OLIVEIRA, A. M. Percurso formativo da Turma Dom José Mauro: segunda turma do curso de Licenciatura e Educação do Campo da FAE-UFMG. In: MOLINA, M. C.; SÁ, L. M. (Orgs.). Licenciaturas em Educação do Campo, Belo Horizonte: Autêntica Editora, 2011. p. 19-34.

RODRIGUES, R. Reflexões sobre a organização curricular por área do conhecimento. In: MOLINA, M. C.; SÁ, L. M. (Orgs.). Licenciaturas em Educação do Campo, Belo Horizonte: Autêntica Editora, 2011. p. 123-147.

THIESEN, J. S. A interdisciplinaridade como um movimento articulador no processo ensino aprendizagem. Revista Brasileira de Educação. V. 13. N. 39. 2008. p. 545-598.

Submetido: 02/05/2019

Aprovado: 19/05/2020

i Universidade Federal de Santa Maria (UFSM). Santa Maria, RS, Brasil. <taminesk8mlks@hotmail.com>
ii Universidade Federal de Santa Maria (UFSM). Santa Maria, RS, Brasil. <crismuenchen@yahoo.com.br> 